\title{
Biological activity of a vascular endothelial cell-hydroxyapatite orbital implant complex: An experimental study
}

\author{
WEIQI WU ${ }^{1,2^{*}}$, HAO LUO $^{1 *}$, DAN WU $^{3}$, MENGLIN SHI $^{1}$, JINHAI YU $^{1}$ and HONGFEI LIAO ${ }^{1}$ \\ ${ }^{1}$ Department of Ocular Oncology and Ocular Trauma, Affiliated Eye Hospital of Nanchang University, \\ Jiangxi Research Institute of Ophthalmology and Visual Sciences, Key Laboratory of Ophthalmology of Jiangxi Province, \\ Nanchang, Jiangxi 330006; ${ }^{2}$ Department of Ophthalmology, The Third Affiliated Hospital of Nanchang University, \\ Jiangxi Key Laboratory of Cancer Metastasis and Precision Treatment, Nanchang, Jiangxi 330008; \\ ${ }^{3}$ Department of Internal Medical, Nanchang HongDu Hospital of Traditional Chinese Medicine, \\ Nanchang, Jiangxi 330006, P.R. China
}

Received August 13, 2021; Accepted December 17, 2021

DOI: $10.3892 /$ etm.2022.11152

\begin{abstract}
The reduction in postoperative complications is a considerable concern after orbital reparation and reconstruction. Selecting the appropriate scaffold materials to improve the survival rates of the seeded cells is a challenge in tissue engineering. The aim of the present study was to evaluate the biological activity of a vascular endothelial cell-hydroxyapatite orbital complex, which was constructed with tissue engineering and used as an implant after enucleation of the eyeNew Zealand white rabbits were randomly divided into two groups that underwent hydroxyapatite orbital implant surgery in the right eye. The primary orbital microvascular endothelial cells were collected from the microvascular tissue and subsequently cultured. Then, hydroxyapatite ocular implants were cultured with vascular endothelial cells in the endothelial cell (EC) group, and implants were cultured without vascular endothelial cells in the blank group. Characterization of the cells was performed with immunofluorescence staining and a Transwell migration and cell tube formation assay. The levels of interleukin-8 (IL-8) and vascular endothelial growth factor (VEGF) in the rabbit conjunctiva were measured with an ELISA. The results showed that the levels of IL- 8 were decreased in the EC group and increased in the blank group. The levels of VEGF were increased in the EC group when compared to the blank group with statistical significance.
\end{abstract}

Correspondence to: Professor Hongfei Liao, Department of Ocular Oncology and Ocular Trauma, Affiliated Eye Hospital of Nanchang University, Jiangxi Research Institute of Ophthalmology and Visual Sciences, Key Laboratory of Ophthalmology of Jiangxi Province, 463 Bayi Road, Nanchang, Jiangxi 330006, P.R. China E-mail:1hfzf@126.com

*Contributed equally

Key words: biological activity, hydroxyapatite, orbital implant complex
The average depth of the fibrovascular tissue was obviously thicker in the EC group compared with that found in the blank group. These findings suggest that the vascular endothelial cell-hydroxyapatite orbital implant complex may be an effective strategy with which to accelerate vascularization and reduce complications of infection with satisfactory biological activity.

\section{Introduction}

Ocular trauma, ocular tumors, or other diseases often lead to enucleation and exenteration of the ocular contents $(1,2)$. After surgery, a local volume defect resulting in orbital depression and orbital deformities may exist even after hydroxyapatite implantation treatment with padding materials (3). The thickness of the orbital wall is 0.3 to $0.9 \mathrm{~mm}$ with a paucity of covered soft tissue, which presents a challenge in reconstructive surgery (4). The common complications of hydroxyapatite implantation include exposure, prolapse, or migration of the implants $(5,6)$. Additionally, it has been reported that the exposure risk of hydroxyapatite implants is closely related to the vascularization of implants in the orbit $(7,8)$. Vascularization in tissue engineering is a complex process. Some investigators have argued that endothelial cells participate in many physiological and pathological processes $(9,10)$. Endothelial cell sprouting from the parent vessels occurs with migration, proliferation, alignment, tube formation, and anastomosis to other vessels (11). Numerous studies have shown that the formation of capillary-like tubes by endothelial cells creates a foundation in in vitro assays (12) or in three-dimensional engineered tissues (13). Coralline porous hydroxyapatite (HA) was the material used in the first porous orbital implant approved by the US Food and Drug Administration for clinical operations in 1989 (14). Early studies reported that the architecture characteristics of porous HA were important for cell perfusion seeding even within large scaffolds (15). In addition, cell proliferation and differentiation were enhanced in the perfusion culture (16). It is increasingly recognized that the angiogenesis process is not only determined by endothelial 
cells, but also by growth factors and scaffolds. Importantly, identification of the cytokines that are expressed, such as proangiogenic factors and inflammatory factors, have led to developments in vascularization. Several reports have shown that vascular endothelial growth factor (VEGF) is upregulated in most proangiogenic pathways (17). Recently, expression of various pro-inflammatory factors, including interleukin (IL)-8, IL-1 and IL-10, were found to be correlated with angiogenesis and effective therapeutics in ophthalmology (18-20). Previous studies have shown that 'pre-vascularization' provides the basis for application of tissue engineering in orbital plastic reconstruction. Preforming a microvasculature in vivo prior to implantation (21) results in acceleration of vascularization in the orbital implant complex.

In the present study, a primary culture of a vascular endothelial cell-hydroxyapatite orbital implant complex was used. We investigated whether it reduced or prevented postoperative infection. The results provide a theoretical basis for the clinical application of tissue engineering techniques in the future.

\section{Materials and methods}

Isolation and culture of rabbit vascular endothelial cells. All animal experiments were carried out in compliance with a protocol specifically approved by the Experimental Animal Center of Nanchang University Animal Care and Use Committee. Ten New Zealand white rabbits $(1.5-2.0 \mathrm{~kg})$ were purchased from Tianqin Biology Technology Co., Ltd. (Hunan, China). Ten rabbits were randomly divided into two groups, namely the endothelial cell (EC) group and the blank group. Vascular endothelial cells of the orbital microvascular tissue in the right eye were extracted from rabbits in the ECs group under local anesthesia of $0.5 \%$ proparacaine hydrochloride ophthalmic solution and 1-2 drops per eye. The tissue samples were washed three times with D-Hanks solution under aseptic conditions using an operating microscope. These specimens were cut into $1-\mathrm{mm}^{3}$ pieces and digested with $0.1 \%$ collagenase I (Beijing Solarbio Science \& Technology Co., Ltd.) for $2 \mathrm{~h}$ at $37^{\circ} \mathrm{C}$ with $5 \% \mathrm{CO}_{2}$. Rabbit vascular endothelial cells were then resuspended in Dulbecco's modified Eagle's medium (DMEM) (Gibco; Thermo Fisher Scientific, Inc.) containing $10 \%$ fetal bovine serum (FBS), $1 \%$ penicillin/streptomycin $(\mathrm{P} / \mathrm{S})$ and $1 \% \mathrm{~L}$-glutamine to terminate digestion. When cell confluency reached $70-80 \%$, the cells in passage three were used in the experiments (22).

Implant preparation. An HA ocular implant was purchased from Beijing Yihuajian Science and Trade Co., Ltd. The average HA ocular implant diameter was approximately $18 \mathrm{~mm}$ and the maximum aperture was $300 \mu \mathrm{m}$. All of the above processes were performed under a sterile environment. Cell seeding into the HA was performed as previously reported (23). The HA ocular implant in the EC group was treated with endothelial cells. The numbers of transplanted cells were $2.0 \times 10^{6}$. The cell-HA implant was cultivated in DMEM containing $10 \% \mathrm{FBS}, 1 \% \mathrm{P} / \mathrm{S}$ and $1 \%$ L-glutamine at $37^{\circ} \mathrm{C}$ with $5 \% \mathrm{CO}_{2}$ for 7 days. The $\mathrm{HA}$ wells did not receive any treatment and served as the blank HA implant group. Culture conditions were the same as that in the EC group.
Evisceration and hydroxyapatite implants. Animal experiments were carried out in accordance with the ARVO Statement for the Use of Animals in Ophthalmic and Vision Research. The study obtained ethics approval from the Ethics Committee of the Affiliated Eye Hospital of Nanchang University (approval no. YLP200810001). The surgical approach for the hydroxyapatite implant was similar to that reported in a previous study (24). All 10 rabbits were anesthetized with intramuscular injections of chlorpromazine $(25 \mathrm{mg} / \mathrm{kg}$ body $\mathrm{wt})$ and ketamine $(50 \mathrm{mg} / \mathrm{kg}$ body $\mathrm{wt})$. The fur was removed at the surgical site in $\sim 3 \mathrm{~cm}$ to prevent contamination. The eyeball of the surgical eyes underwent iodophor disinfectant $(250 \mathrm{mg} / \mathrm{l})$ and $0.9 \%$ sodium chloride injection for douching repeatedly. All rabbits received evisceration of the right eye in a sterile environment, which was finished with oculis. The rabbits of the EC group received implants of the cell-HA complex into the orbit, which was then sutured and fixed to the temporalis muscle and frontal muscle flap. The same operations were conducted in the blank group except the blank-HA complex was implanted. Benzylpenicillin $(400,000 \mathrm{U})$ was injected over the following 3 days to prevent inflammation. Fifteen days after surgery, the implants in the two groups were extracted from the orbits of the experimental animals. Rabbits were euthanized by i.v. injection of pentobarbital with $100 \mathrm{mg} / \mathrm{kg}$.

Immunofluorescent assay. Immunofluorescent assay processes were similar to those reported in a previous study (25). Rabbit vascular endothelial cells were seeded on sterile coverslips in a 24-well plate in DMEM with 10\% FBS. Twenty-four hours later, the cells were washed three times with PBS and fixed with $4 \%$ paraformaldehyde for $30 \mathrm{~min}$ at $37^{\circ} \mathrm{C}$. The cells were rinsed with PBS for $3 \times 5$ min, penetrated with $0.5 \%$ Triton $\mathrm{X}-100$ in PBS for $20 \mathrm{~min}$, and then blocked in 10\% FBS for $2 \mathrm{~h}$. They were then incubated with a 1:100 von Willebrand factor (vWF) primary antibody (cat. no. 66682-1-lg; ProteinTech Group, Inc.) in a wet box at $4^{\circ} \mathrm{C}$ in the dark. Then, the cells were incubated with a 1:150 dilution of goat anti-mouse $\operatorname{lgG}$ $(\mathrm{H}+\mathrm{L})$ Cross-Adsorbed secondary antibody, Alexa Fluor 594 (cat. no. SA00006-3; ProteinTech Group, Inc.) in the dark for $1 \mathrm{~h}$ and stained with 4',6-diamidino-2-phenylindole (DAPI). Fluorescent images were acquired with a fluorescence inverted microscope (IX73; Olympus Corporation).

Cell tube formation assay. Cell tube formation assays were conducted as previously reported (25). In brief, all products that were exposed to the Matrigel matrix (Corning, Inc.) adhesive were placed in a refrigerator at $-20^{\circ} \mathrm{C}$ for $6 \mathrm{~h}$. Matrigel was precooled to a basal medium at $4^{\circ} \mathrm{C}$ for $24 \mathrm{~h}$. Matrigel was added per well into 96-well plates with $60 \mu \mathrm{l}$ and then placed at $37^{\circ} \mathrm{C}$ for $2 \mathrm{~h}$. Rabbit vascular endothelial cells were seeded onto the Matrigel bed $\left(1.5 \times 10^{4}\right.$ cells/well $)$ and cultured for $4 \mathrm{~h}$. Tube formation was imaged and assessed with ImageJ software (version 1.52; National Institutes of Health).

Transwell cell migration assay. Endothelial cells were seeded into the upper level of a Transwell chamber at a density of 1.0x $10^{5}$ cells/chamber, and the lower level was filled with $600 \mu \mathrm{l}$ medium containing 10\% FBS in the EC group and $600 \mu \mathrm{l}$ in serum-free medium in the blank group. Cells were cultured 

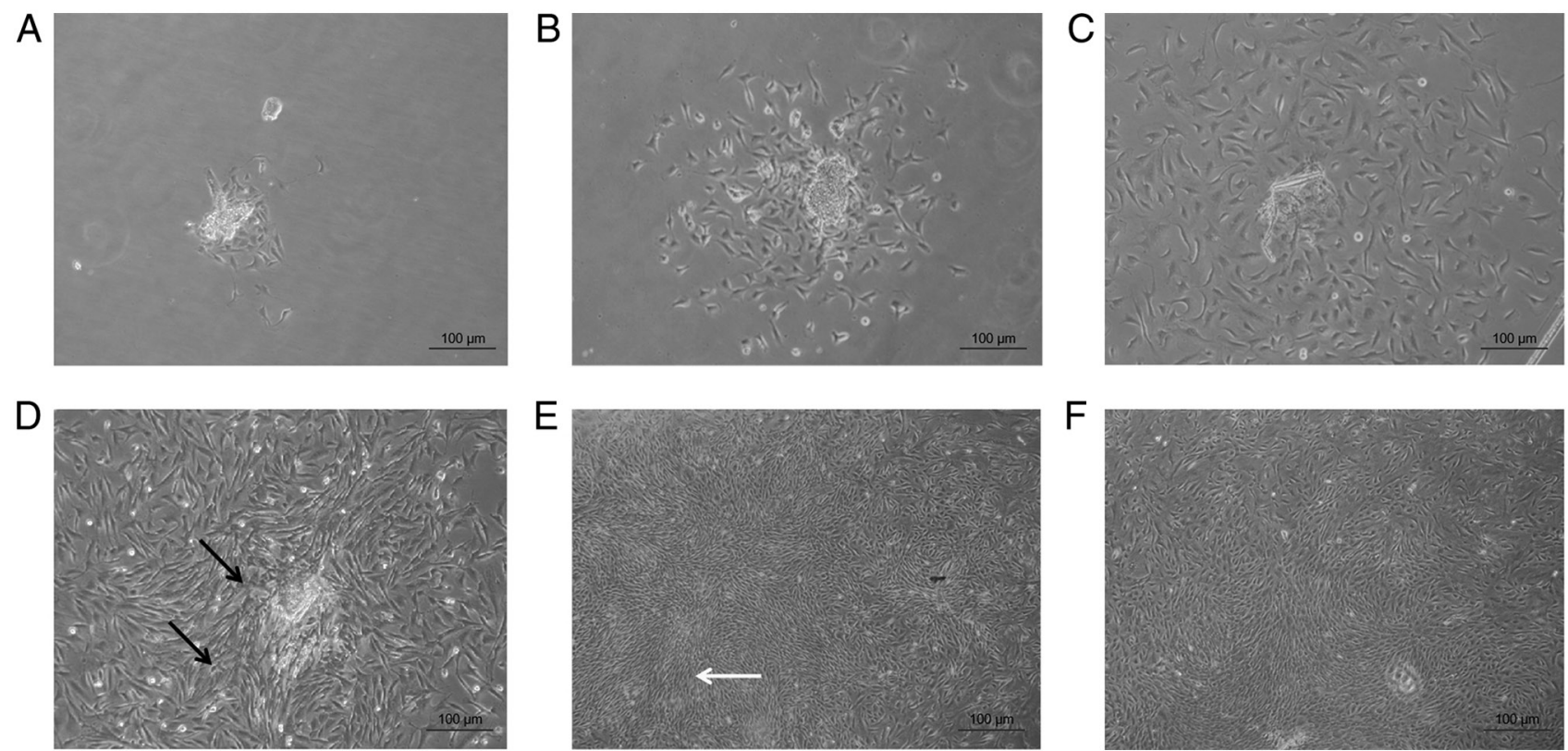

Figure 1. Primary rabbit vascular endothelial cells in each group under an inverted microscope (x100 magnification). Primary rabbit vascular endothelial cells were extracted after culturing for (A) 4 days, (B) 7 days, (C) 10 days and (D) 13 days (endothelial cells indicated by the black arrow). (E and F) Primary rabbit vascular endothelial cells were cultured and underwent normal growth and reproduction in passage three with a paucity of fibroblast-like cells (indicated by the white arrow).

at $37^{\circ} \mathrm{C}$ with $5 \% \mathrm{CO}_{2}$ for $16 \mathrm{~h}$. Subsequently, the cells that had invaded the lower surface of the membrane were fixed for 25 min with $4 \%$ paraformaldehyde, stained with $0.25 \%$ crystal violet dye for $5 \mathrm{~min}$, and then rinsed with PBS several times. Cells that had not migrated were gently removed using a cotton swab once the chambers had dried. The number of migrated cells were counted and imaged with a microscope as previously described (25). The Transwell migration assays were performed in triplicate.

Implant histopathological examination. Implant samples were embedded in paraffin in $5-\mu \mathrm{m}$ serial sections. H\&E was used to stain the implants. The slides were examined under a light microscope with a photomicrographic attachment as previously described (26). Pathologists examined all H\&E-stained slides from both the blank and EC groups, and diagnosed various inflammatory cell infiltration (such as neutrophils and eosinophils) according to the cellular morphological features.

ELISA. ELISAs were performed according to the manufacturer's guidelines (Boster Biological Technology). The rabbits received intramuscular injections of chlorpromazine $(25 \mathrm{mg} / \mathrm{kg}$ body wt) and ketamine (50 mg/kg body wt) for anesthesia, and the right eye was exposed with a lid speculum at 3, 10, 15 days after implantation. The conjunctiva flap at fornix was collected from each group and fully broken down fully in liquid nitrogen. Then, the samples were diluted five times in PBS and centrifuged at $4^{\circ} \mathrm{C}$ for $10 \mathrm{~min}$ at $12,000 \mathrm{x} \mathrm{g}$. Additionally, the supernatants were collected for secretion measurement. Prior to the experiment (27), the detection reagent and each group of samples were pipetted onto pre-coated plates that had been coated with rabbit interleukin-8 (IL-8) and vascular endothelial growth factor (VEGF) antibodies. The optical density value was determined at $450 \mathrm{~nm}$ by enzyme-labeled analyzer immediately.
Statistical analysis. All data are reported as the mean \pm SD, and each experiment was repeated more than three times. The statistical significance of differences was determined using Student's t-test for the in vitro study. $\mathrm{P}<0.05$ was considered to indicate a statistically significant difference.

\section{Results}

Cell isolation and characterization. Primary rabbit vascular endothelial cells were observed, and images were captured under an inverted microscope at x100 magnification. At 13 days after cell culture, fusiforms were observed, as shown in Fig. 1. Immunofluorescence staining showed the distribution of vWF in primary rabbit vascular endothelial cells with $>90 \%$ of vWF-positive cells (Fig. 2). Migration of the primary vascular endothelial cells was assessed using a Transwell assay. The number of cells in the EC group was 456 \pm 38.74 , which was significantly increased when compared to the blank group (206.33 \pm 13.32$)(P<0.001$; Fig. 3). Tube formation occurred in the primary cells and was observed under a microscope after culturing for $4 \mathrm{~h}$ (Fig. 4).

Primary vascular endothelial cells grown in the HA implant. Primary rabbit vascular endothelial cells were inoculated to the HA ocular implant $\left(2.0 \times 10^{6}\right.$ cells $\left./ \mathrm{ml}\right)$ and cultured for 7 days before evisceration. As for the particular structure of the HA implant, cells grew well inside the interiors of the pore walls (Fig. 5). This process was used to create the vascular endothelial cell-HA orbital implant complex shown in Fig. 6.

Comparison of fibrovascularization and inflammatory cell infiltration. All rabbits underwent evisceration in the right eye and the EC group received a cell-HA orbital complex implant. The blank-HA complex was implanted in the blank group. At 15 days after surgery, the implants in the EC group and 

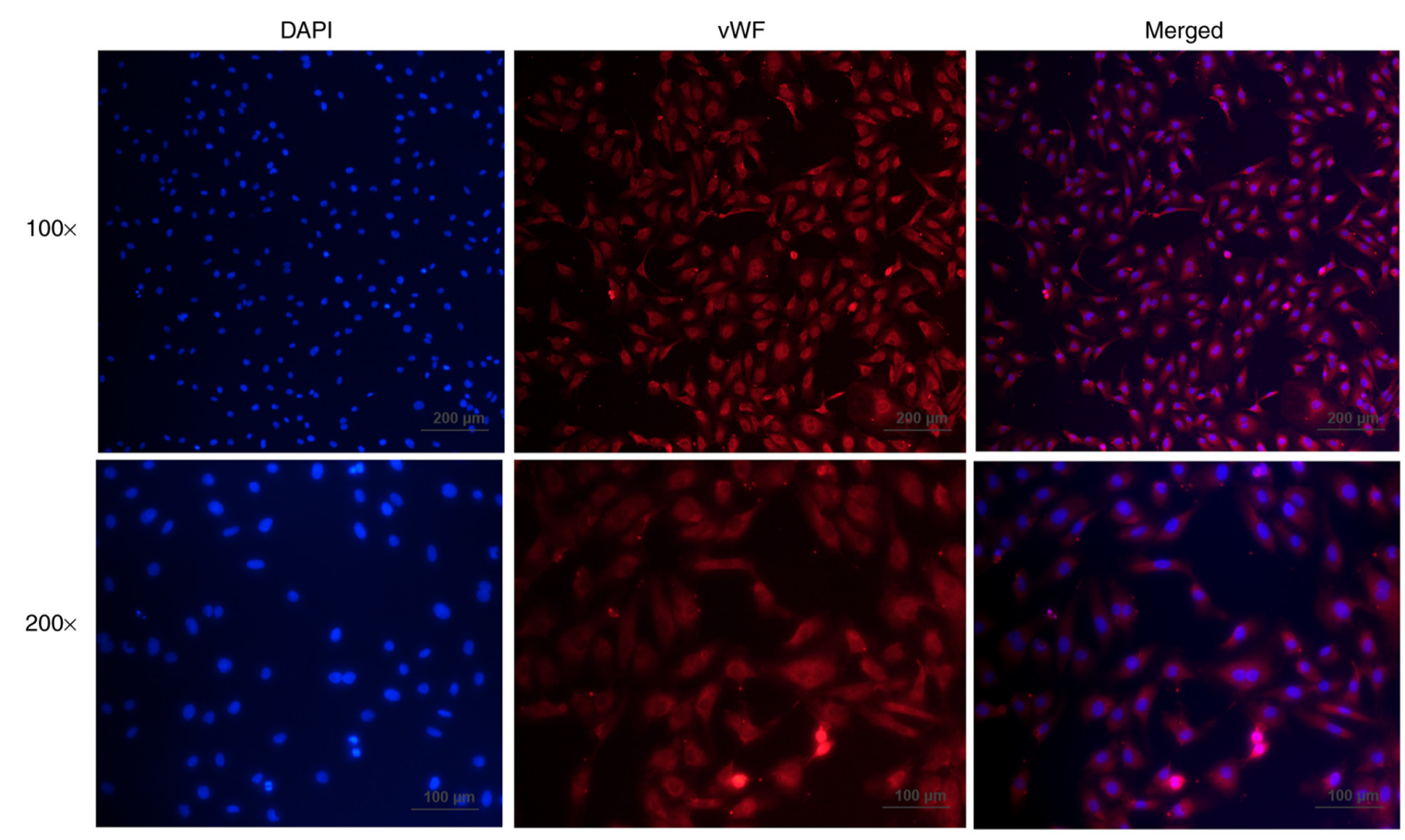

Figure 2. Images were acquired using laser scanning confocal microscopy under x100 and x200 objectives. Nuclei were stained with DAPI using a blue filter. Cytoplasmic and perinuclear tissues were stained and showed fluorescence, as shown in red. vWF, von Willebrand factor.
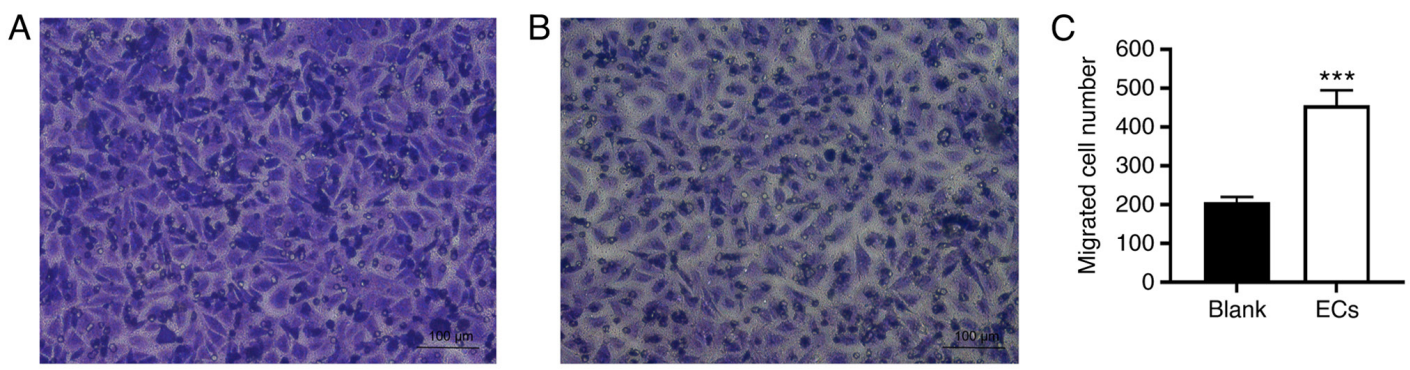

Figure 3. Migration of transfected rabbit vascular endothelial cells. Representative images of Transwell migration in the (A) blank and (B) EC group. (C) Quantification of migration. ${ }^{* * *} \mathrm{P}<0.001$ vs. blank group.
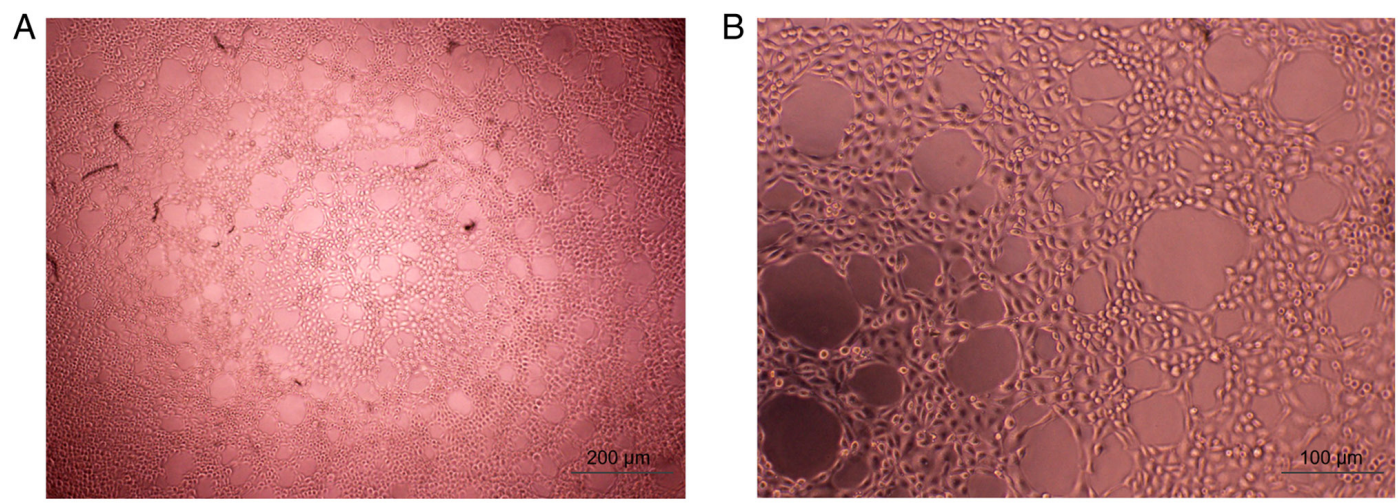

Figure 4. Tube formation in rabbit vascular endothelial cells. Images were observed using an inverted microscope: (A) x100 magnification and (B) x200 magnification.

blank group were extracted from the orbits of the experimental animals. H\&E staining showed that fibrovascular ingrowth in the implants was clearly observed in the EC group, but inapparent in the blank group (Fig. 7A and B). The insertion depth $(\mathrm{mm})$ of neovascularization was $1.38 \pm 0.35 \mathrm{~mm}$ in the EC group, which was significantly higher when compared with that in the blank group $(0.06 \pm 0.12 \mathrm{~mm})(\mathrm{P}<0.05$; Fig. 7C). At day 15 , both connective tissues and blood vessels were clearly 

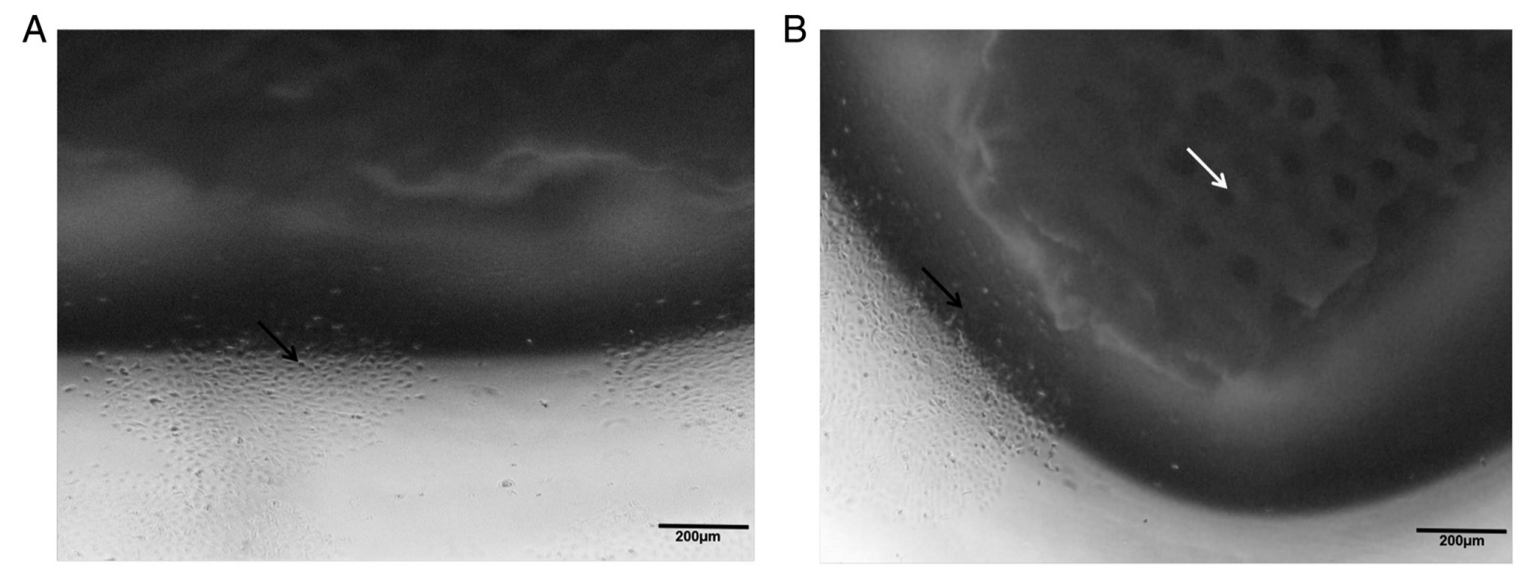

Figure 5. Image showing that rabbit vascular endothelial cells were able to grow in scaffold materials of the HA implant with an initial cell density of $2.0 \times 10^{6} \mathrm{cells} / \mathrm{ml}$. (A) Endothelial cells grown in the HA implant (indicated by the black arrow), (B) with a porous structure (indicated by the white arrow). HA, hydroxyapatite.
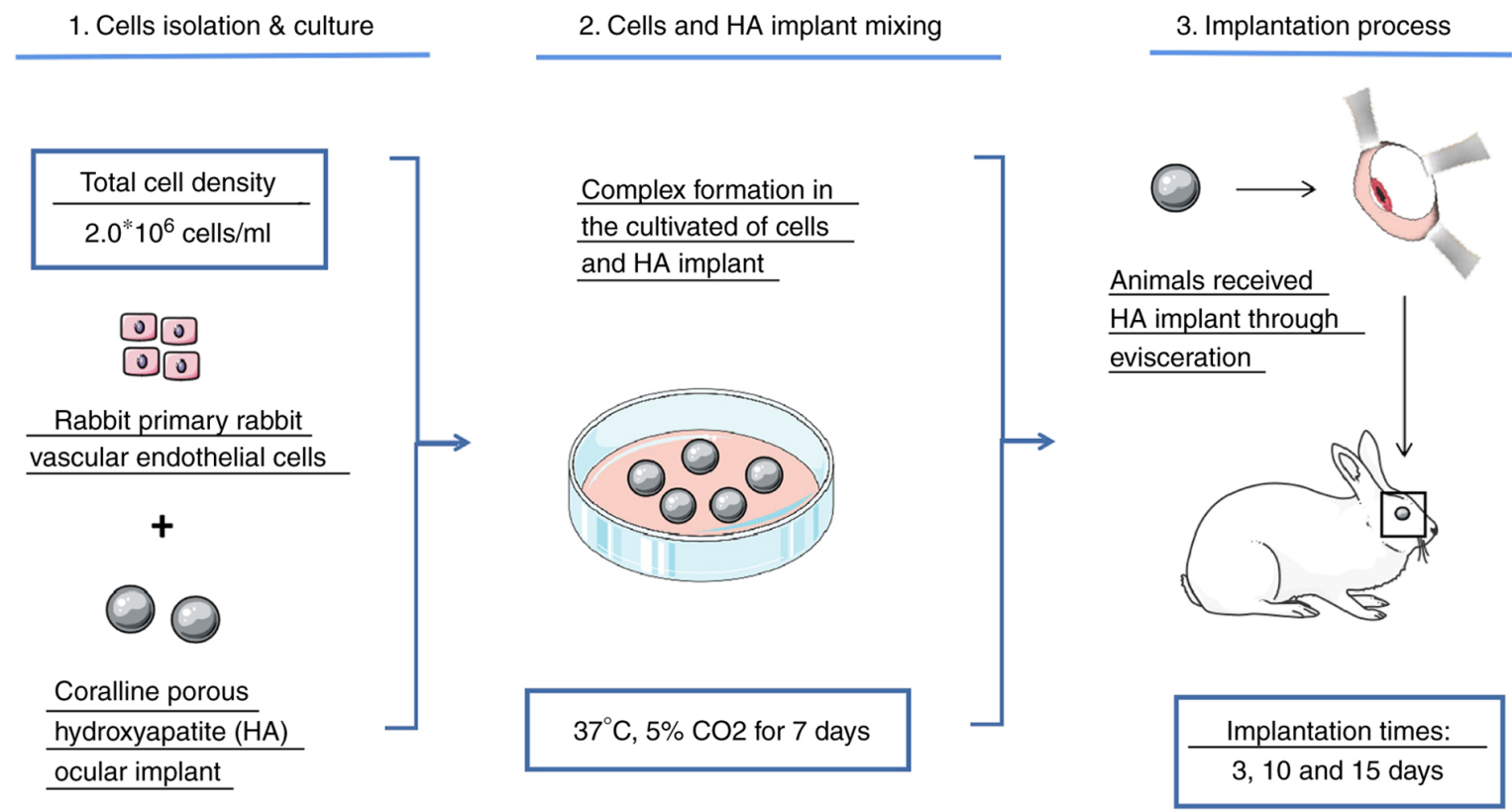

Figure 6. Implantation process. Rabbit vascular endothelial cells were incorporated into the HA ocular implant. Subsequently, the resultant cell-HA and blank-HA complexes were implanted into the orbits of the rabbits, cultured for 3, 10, and 15 days, and then analyzed for the subsequent experiments. HA, hydroxyapatite.

observed in the EC group, but not in the blank group. The histopathological images of implantation in the blank group showed evidence of inflammatory cell infiltration which indicated by polymorphonuclear neutrophils and eosinophils. Numerous round cells with obscure margins were presented in the edge zones with occasional macrophage in the blank group. The neutrophils and eosinophils were interspersed in the EC group, which indicated that inflammatory cell infiltration in the blank group was higher than that in the EC group (Fig. 8).

Levels of IL-8 and VEGF. An ELISA was used to measure the levels of rabbit inflammatory factor IL-8 in the conjunctiva homogenate of the EC group and blank group at 3, 10, and 15 days after implantation. At day 3 , the two groups showed similar levels of IL-8, without statistical significance, which then decreased over time in the culture as cells proliferated. At day 15, the differences reached statistical significance when compared to the preoperative levels with $84.72 \pm 38.88 \mathrm{pg} / \mathrm{ml}$ in the EC group and $230.78 \pm 41.62 \mathrm{pg} / \mathrm{ml}$ in the blank group $(\mathrm{P}<0.001$; Fig. 9A). The levels of rabbit angiogenesis factor VEGF in the EC group at days 3, 10, and 15 after implantation were $101.32 \pm 23.62,160.28 \pm 13.22$, and $619.83 \pm 48.65 \mathrm{pg} / \mathrm{ml}$, respectively, which were significantly higher than those in the blank group, $(8.32 \pm 3.86,13.92 \pm 3.37$, and $11.53 \pm 6.08 \mathrm{pg} / \mathrm{ml} ; \mathrm{P}<0.01$ vs. day $3, \mathrm{P}<0.001$ vs. days 10 and 15; Fig. 9B).

\section{Discussion}

Tissue engineering technology has been employed successfully in the management of orbital diseases (28). Endothelial cells, 

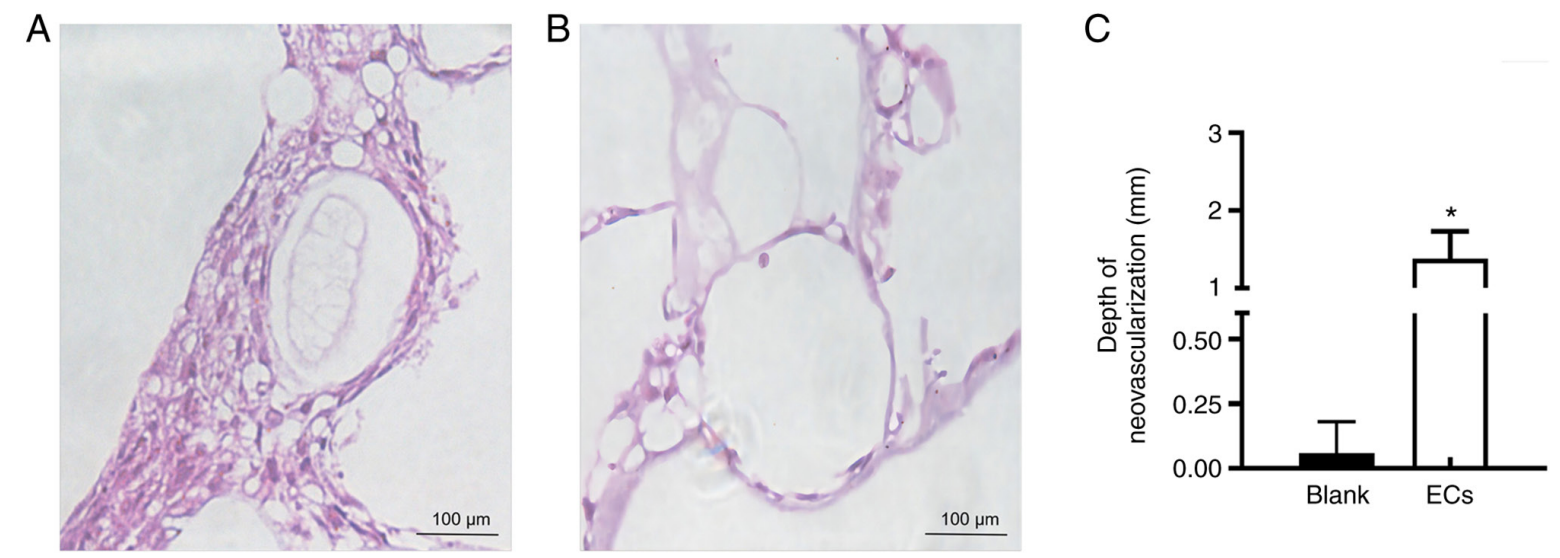

Figure 7. Representative images of the fibrovascular tissue. Obvious ingrowth into the implant was (A) significantly increased in the ECs group and (B) sparsely increased in the blank group. (C) Statistical differences are noted between conditions. ${ }^{*} \mathrm{P}<0.05$ vs. blank group. EC, endothelial cell.
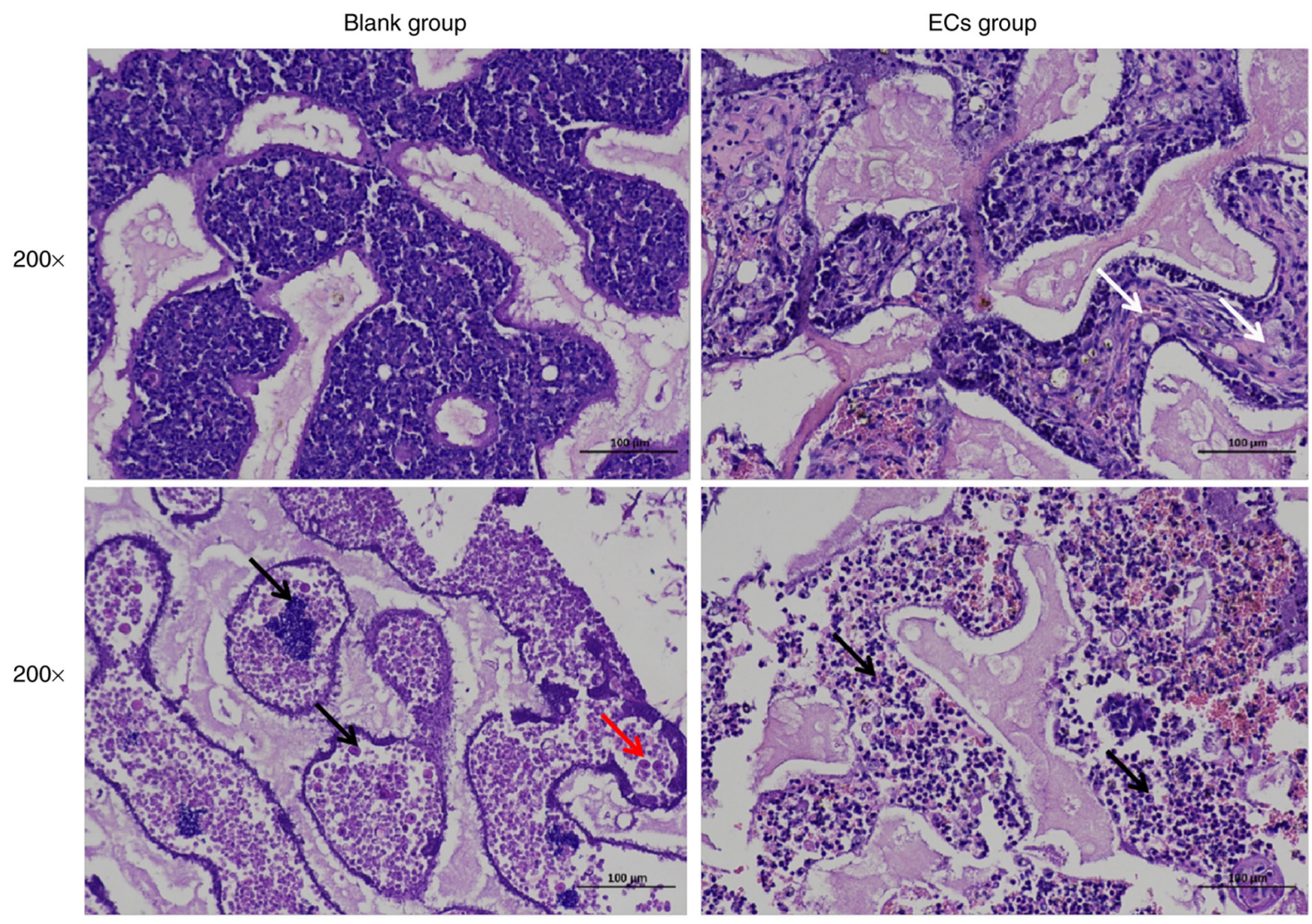

Figure 8. Photomicrographs (magnification x200). Obvious connective tissue and blood vessels were observed in cell-implants with scattered vacuole bodies (indicated by the white arrows) in the EC group and not observed in the blank group. The numbers of inflammatory cells mainly neutrophils, and cell necrosis in eosinophils (indicated by the black arrows) and foamy macrophages (indicated by the red arrow) were observed in the blank group. There were scattered neutrophils diffused in the EC group (indicated by the black arrow). EC, endothelial cell.

as the seeded cells, play an important role in the in vitro formation of the perivascular network (29). Previous endothelial cell-related research has mostly focused on human umbilical vein endothelial cells and their angiogenic responses (30). Early reports (31) suggested that rabbit bone marrow mononuclear cell-derived endothelial cells can improve the vascularization of bone replacements. Tan et al (32) showed that isolation of vascular endothelial stem cells from liver tissue possess high proliferative and revascularization potential. In our study, isolated endothelial cells from microvascular tissue were conveniently obtained with less trauma and they had high self-replication compared to other tissue-derived endothelial cells. There have also been reports on an anti-inflammatory role for endothelial cells $(33,34)$ with prevention of infection and postoperative complications. These results suggest that endothelial cells are involved in dynamic equilibrium with inflammatory mediators and angiogenic factors. HA has good biocompatibility and provides a reticular structure for fibrovascular ingrowth into the implant. It is widely used in the repair of bone defects $(35,36)$. In our study, the HA implant was seeded with primary vascular endothelial cells that were extracted from microvascular endothelial tissue to avoid 
A

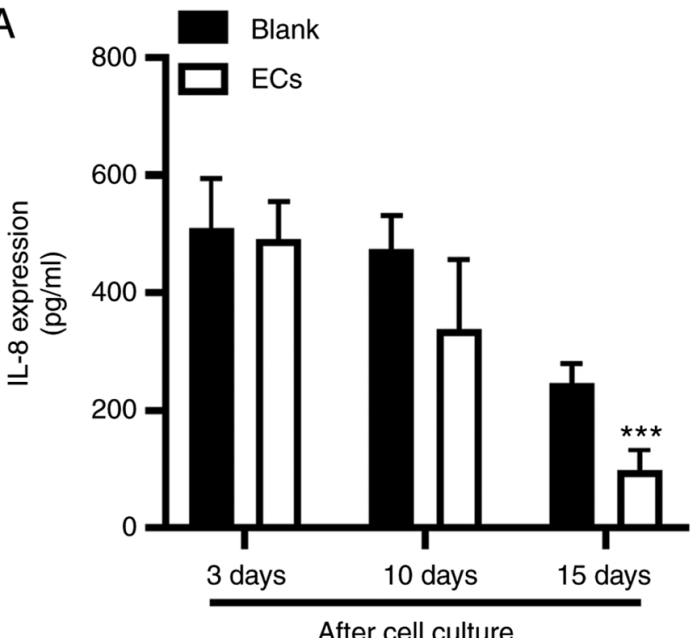

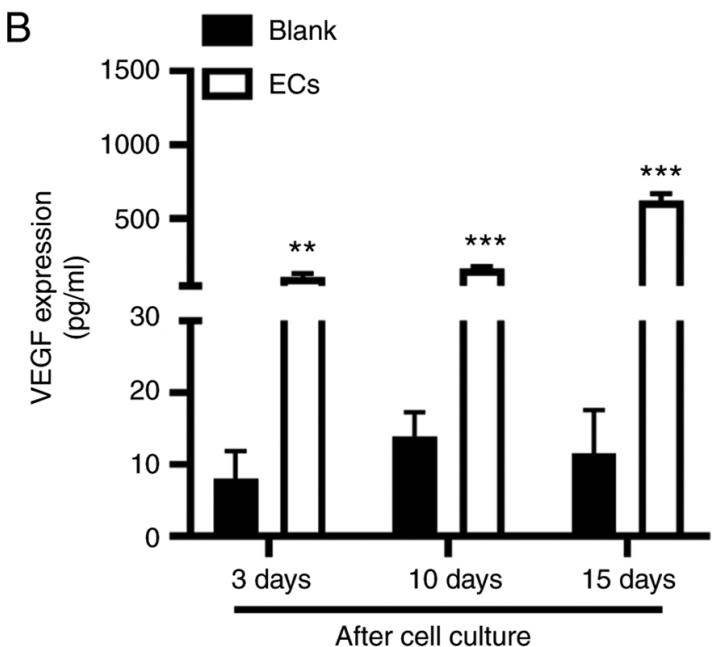

Figure 9. Levels of IL-8 and VEGF in rabbit conjunctiva homogenate were detected using an ELISA. (A) The production of IL-8 was obviously decreased in the EC group at day 15 after implantation. ${ }^{* * * *} \mathrm{P}<0.001$ vs. 15 days blank group. (B) The levels of VEGF were significantly higher in the EC group at days 3 , 10 , and 15 compared with the blank group. ${ }^{* *} \mathrm{P}<0.01$ and ${ }^{* * *} \mathrm{P}<0.001$ vs. respective blank groups. IL, interleukin; VEGF, vascular endothelial growth factor; EC, endothelial cell.

rejection. It is important to determine the extraction rate and proliferation of vascular endothelial cells in vitro.

In the present study, ELISA experiments and pathological sections were used to demonstrate the activity of the complex in vivo. IL-8, as one of the key proinflammatory cytokines, plays an important role in modulating the inflammatory response. The levels of IL- 8 are associated with the progress and severity of a disease state, including diabetes, atherosclerosis, and various forms of liver injury $(37,38)$. The present study found that IL-8 expression was significantly lower than in the blank group, suggesting that local revascularization in the EC group might be enhanced when compared with that of the blank group. Pathological sections showed that fibrovascular ingrowth in the EC group was markedly higher than in the blank group, which indicated a severe inflammatory reaction with aggregation of mycelial pellets and scattered macrophages in the blank group. This study demonstrated that the degree of vascularization and the inflammatory reaction were approximately inverse in proportion.

Vascular endothelial growth factor (VEGF) is an essential growth factor that can promote angiogenesis and vascular permeability (39). Due to the large individual variations, gross changes in the local tissues, healing of the conjunctival incision, and molding of the HA were investigated after the operation with no significant difference between the two groups. Specifically, it was demonstrated that the isolation of orbital microvascular tissue and scaffold material of HA provided an experimental basis both in vitro and in vivo. These data suggest that the cell-hydroxyapatite orbital implant complex had satisfactory biological activity in experimental animals.

Postoperative complications of hydroxyapatite orbital implantation, such as implant exposure, implant migration conjunctival infection, conjunctival chronic discharge, and conjunctival cysts, are inevitable (40). Previous reports have shown that infection is a serious problem for orbital implants and it requires antibiotic injection or surgical interventions (41). It was documented that infection occurred in $5.19 \%$ in a series of 212 patients with HA implants over a period of
12 years (42). Catalu et al (43) reported that radical surgery (evisceration or enucleation) can reduce the occurrence of ocular infections. Thus, we investigated the biological activity of a vascular endothelial cell-hydroxyapatite orbital implant complex intraoperatively, which can promote and improve the clinical treatment of orbital implantation. However, there are some limitations to the present study. The efficacy of HA transplantation was not thoroughly evaluated and whether or not there are other factors in the process of blood vessels was not assessed. We speculate that IL-8 is related to postoperative anti-inflammatory effects, but more experiments, including expression of other inflammatory factors, are needed to confirm this speculation. In the future, it is necessary to provide reference data for clinical operations and explore the possible mechanisms of vascularization.

\section{Acknowledgements}

Not applicable.

\section{Funding}

This study was supported by the Natural Science Foundation of China (no. 82060181) and Innovation Fund Designated for Graduate Students of Jiangxi Province (no. YC2019-S040).

\section{Availability of data and materials}

The datasets used and/or analyzed during the current study are available from the corresponding author on reasonable request.

\section{Authors' contributions}

WW and HLu contributed to the conception and design of the study and manuscript preparation. DW, MS and JY performed the data collection, interpretation and statistical analysis. WW and JY confirmed the authenticity of all the raw data. HLi designed the study, analyzed the data and wrote the paper. 
All authors have read and approved the final manuscript for publication.

\section{Ethics approval and consent to participate}

This study was approved by the Ethics Committee of the Affiliated Eye Hospital of Nanchang University (no. YLP200810001). All animal experiments were carried out in compliance with a protocol specifically approved by the Experimental Animal Center of Nanchang University Animal Care and Use Committee.

\section{Patient consent for publication}

Not applicable.

\section{Competing interests}

The authors declare that they have no competing interests.

\section{References}

1. Sahraravand A, Haavisto AK, Holopainen JM and Leivo T: Ocular trauma in the finnish elderly-helsinki ocular trauma study. Acta Ophthalmol 96: 616-622, 2018.

2. Zhao Y, Zhao H, Lin JY, Pan Y, Zhai WJ and Wang YC: Clinical and pathological analysis of ocular tumors in 504 children cases. Zhonghua Yan Ke Za Zhi 52: 764-768, 2016 (In Chinese).

3. Pförtner R, Mohr C, Daamen J and Metz A: Orbital tumors: Operative and therapeutic strategies. Facial Plast Surg 30: 570-577, 2014.

4. Kasper FK, Melville J, Shum J, Wong M and Young S: Tissue engineered prevascularized bone and soft tissue flaps. Oral Maxillofac Surg Clin North Am 29: 63-73, 2017.

5. Bee YS, Lin MC, Sheu SJ and Ng JD: Elevated white blood cell count may predict risk of orbital implant exposure. Can J Ophthalmol 49: 45-49, 2014.

6. Lu L, Shi W, Luo M, Sun Y and Fan X: Repair of exposed hydroxyapatite orbital implants by subconjunctival tissue flaps. J Craniofac Surg 22: 1452-1456, 2011.

7. Buettner H and Bartley GB: Tissue breakdown and exposure associated with orbital hydroxyapatite implants. Am J Ophthalmol 113: 669-673, 1992.

8. Zhao Y, Zhang MN, Gao YX, Gao XW and Ren B: Comparative study of modified and conventional secondary hydroxyapatite orbital implantations. Int J Ophthalmol 6: 646-649, 2013.

9. Rioja AY, Annamalai RT, Paris S, Putnam AJ and Stegemann JP: Endothelial sprouting and network formation in collagen- and fibrin-based modular microbeads. Acta Biomater 29: 33-41, 2016.

10. Rouwkema J and Khademhosseini A: Vascularization and angiogenesis in tissue engineering: Beyond creating static networks. Trends Biotechnol 34: 733-745, 2016.

11. Dai B, Zhang Y, Zhan Y, Zhang D, Wang N and He L: A novel tissue model for angiogenesis: Evaluation of inhibitors or promoters in tissue level. Sci Rep 4: 3693, 2014.

12. Ayata RE, Chabaud S, Auger M and Pouliot R: Behaviour of endothelial cells in a tridimensional in vitro environment. Biomed Res Int 2015: 630461, 2015.

13. Caneparo C, Baratange C, Chabaud S and Bolduc S: Conditioned medium produced by fibroblasts cultured in low oxygen pressure allows the formation of highly structured capillary-like networks in fibrin gels. Sci Rep 10: 9291, 2020.

14. Ye J, Gao Q, He JJ, Gao T, Ning QY and Xie JJ: Exposure rate of unwrapped hydroxyapatite orbital implants in enucleation surgery. Br J Ophthalmol 100: 860-865, 2016.

15. Li J, Zhi W, Xu T, Shi F, Duan K, Wang J, Mu Y and Weng J: Ectopic osteogenesis and angiogenesis regulated by porous architecture of hydroxyapatite scaffolds with similar interconnecting structure in vivo. Regen Biomater 3: 285-297, 2016.

16. Wang L, Ma XY, Zhang Y, Feng YF, Li X, Hu YY, Wang Z Ma ZS and Lei W: Repair of segmental bone defect using Totally Vitalized tissue engineered bone graft by a combined perfusion seeding and culture system. PLoS One 9: e94276, 2014.
17. Brauer MJ, Zhuang G, Schmidt M, Yao J, Wu X, Kaminker JS, Jurinka SS, Kolumam G, Chung AS, Jubb A, et al: Identification and analysis of in vivo VEGF downstream markers link VEGF pathway activity with efficacy of anti-VEGF therapies. Clin Cancer Res 19: 3681-3692, 2013.

18. Paulitti A, Andreuzzi E, Bizzotto D, Pellicani R, Tarticchio G, Marastoni S, Pastrello C, Jurisica I, Ligresti G, Bucciotti F, et al: The ablation of the matricellular protein EMILIN2 causes defective vascularization due to impaired EGFR-dependent IL-8 production affecting tumor growth. Oncogene 37: 3399-3414, 2018.

19. Protopsaltis NJ, Liang W, Nudleman E and Ferrara N: Interleukin-22 promotes tumor angiogenesis. Angiogenesis 22: 311-323, 2019.

20. Wooff Y, Man SM, Aggio-Bruce R, Natoli R and Fernando N: IL-1 family members mediate cell death, inflammation and angiogenesis in retinal degenerative diseases. Front Immunol 10: $1618,2019$.

21. Laschke MW and Menger MD: Prevascularization in tissue engineering: Current concepts and future directions. Biotechnol Adv 34: 112-121, 2016.

22. Lei M, Wang K, Li S, Zhao K, Hua W, Wu X and Yang C: The c-Jun signaling pathway has a protective effect on nucleus pulposus cells in patients with intervertebral disc degeneration. Exp Ther Med 20: 123, 2020.

23. Jin K, Ye X, Li S, Li B, Zhang C, Gao C and Ye J: A biomimetic collagen/heparin multi-layered porous hydroxyapatite orbital implant for in vivo vascularization studies on the chicken chorioallantoic membrane. Graefes Arch Clin Exp Ophthalmol 254: 83-89, 2016.

24. Lee H and Baek S: Comparison of early fibrovascular proliferation according to orbital implant in orbital floor fracture reconstruction. J Craniofac Surg 23: 1518-1523, 2012.

25. Li Z, Liang J, Wu WK, Yu X, Yu J, Weng X and Shen J: Leptin activates RhoA/ROCK pathway to induce cytoskeleton remodeling in nucleus pulposus cells. Int J Mol Sci 15: 1176-1188, 2014.

26. Yang WJ, Yan JB, Zhang L, Zhao F, Mei ZM, Yang YN, Xiang Y and Xing YQ: Paxillin promotes the migration and angiogenesis of HUVECs and affects angiogenesis in the mouse cornea. Exp Ther Med 20: 901-909, 2020

27. Jiang Z, Wang J, Li X and Zhang X: Echinacoside and Cistanche tubulosa (Schenk) R. wight ameliorate bisphenol A-induced testicular and sperm damage in rats through gonad axis regulated steroidogenic enzymes. J Ethnopharmacol 193: 321-328, 2016.

28. Fathi E, Farahzadi R, Vietor I and Javanmardi S: Cardiac differentiation of bone-marrow-resident c-kit ${ }^{+}$stem cells by L-carnitine increases through secretion of VEGF, IL6, IGF-1, and TGF- $\beta$ as clinical agents in cardiac regeneration. J Biosci 45: $92,2020$.

29. Zhou H and Lee J: Nanoscale hydroxyapatite particles for bone tissue engineering. Acta Biomater 7: 2769-2781, 2011.

30. Zhang X, Yang J, Li Y, Liu S, Long K, Zhao Q, Zhang Y, Deng Z and Jin Y: Functional neovascularization in tissue engineering with porcine acellular dermal matrix and human umbilical vein endothelial cells. Tissue Eng Part C Methods 17: 423-433, 2011.

31. Du P, Subbiah R, Park JH and Park K: Vascular morphogenesis of human umbilical vein endothelial cells on cell-derived macromolecular matrix microenvironment. Tissue Eng Part A 20: 2365-2377, 2014

32. Tan H, Yang B, Duan X, Wang F, Zhang Y, Jin X, Dai G and Yang L: The promotion of the vascularization of decalcified bone matrix in vivo by rabbit bone marrow mononuclear cell-derived endothelial cells. Biomaterials 30: 3560-3566, 2009.

33. Naito H, Wakabayashi T, Ishida M, Gil CH, Iba T, Rahmawati FN, Shimizu S, Yoder MC and Takakura N: Isolation of tissue-resident vascular endothelial stem cells from mouse liver. Nat Protoc 15: 1066-1081, 2020.

34. Iba T and Levy JH: Inflammation and thrombosis: Roles of neutrophils, platelets and endothelial cells and their interactions in thrombus formation during sepsis. J Thromb Haemost 16: 231-241, 2018.

35. Okamoto T, Akita N, Terasawa M, Hayashi T and Suzuki K: Rhamnan sulfate extracted from Monostroma nitidum attenuates blood coagulation and inflammation of vascular endothelial cells. J Nat Med 73: 614-619, 2019.

36. Swetha M, Sahithi K, Moorthi A, Srinivasan N, Ramasamy K and Selvamurugan N: Biocomposites containing natural polymers and hydroxyapatite for bone tissue engineering. Int J Biol Macromol 47: 1-4, 2010. 
37. Gradinaru S, Popescu V, Leasu C, Pricopie S, Yasin S, Ciuluvica R and Ungureanu E: Hydroxyapatite ocular implant and non-integrated implants in eviscerated patients. J Med Life 8: 90-93, 2015.

38. Joshi-Barve S, Barve SS, Amancherla K, Gobejishvili L, Hill D, Cave M, Hote $\mathrm{P}$ and McClain CJ: Palmitic acid induces production of proinflammatory cy tokine interleukin- 8 from hepatocytes. Hepatology 46: 823-830, 2007.

39. Jaeschke $\mathrm{H}$ : Inflammation in response to hepatocellular apoptosis. Hepatology 35: 964-966, 2002.

40. Alkharsah KR: VEGF upregulation in viral infections and its possible therapeutic implications. Int J Mol Sci 19: 19, 2018.

41. Sobti MM, Shams F, Jawaheer L, Cauchi P and Chadha V: Unwrapped hydroxyapatite orbital implants: Our experience in 347 cases. Eye (Lond) 34: 675-682, 2020
42. Karsloğlu S, Serin D, Simșek I and Ziylan S: Implant infection in porous orbital implants. Ophthal Plast Reconstr Surg 22: 461-466, 2006

43. Catalu CT, Istrate SL, Voinea LM, Mitulescu C, Popescu V and Radu C: Ocular implants-methods of ocular reconstruction following radical surgical interventions. Rom J Ophthalmol 62: $15-23,2018$.

This work is licensed under a Creative Commons Attribution-NonCommercial-NoDerivatives 4.0 International (CC BY-NC-ND 4.0) License. 